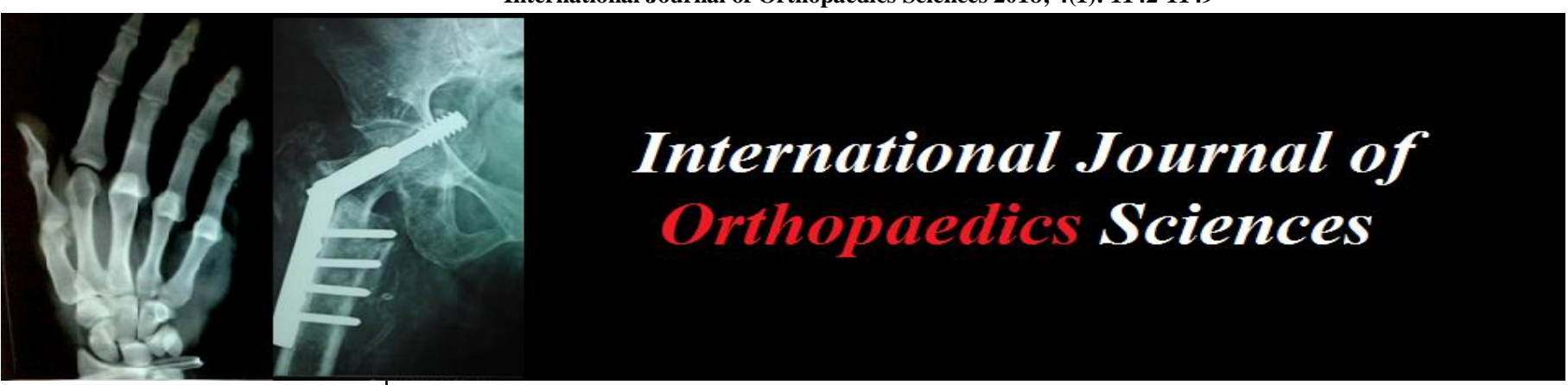

ISSN: $2395-1958$

IJOS 2018; 4(1): 1142-1149

(C) 2018 IJOS

www.orthopaper.com

Received: 15-11-2017

Accepted: 16-12-2017

Janak Das Kathabaniya MS Ortho, Department of Orthopaedic Surgery, B.P.

Koirala Institute of Health Sciences, Dharan, Sunsari, Nepal

Bikram Prasad Shrestha Professor, Department of Orthopaedic Surgery, B.P. Koirala Institute of Health Sciences, Dharan, Sunsari, Nepal

\section{Rajiv Maharjan}

Additional Professor,

Department of Orthopaedic Surgery, B.P. Koirala Institute of Health Sciences, Dharan, Sunsari, Nepal

Rosan Prasad Shah

Associate Professor, Department of Orthopaedic Surgery, B.P. Koirala Institute of Health Sciences, Dharan, Sunsari, Nepal

Jeevan Kumar Sharma MS Ortho, Department of Orthopaedic Surgery, B.P. Koirala Institute of Health Sciences, Dharan, Sunsari, Nepal

Correspondence

Janak Das Kathabaniya MS Ortho, Department of Orthopaedic Surgery, B.P. Koirala Institute of Health Sciences, Dharan, Sunsari, Nepal

\section{The effect of alfacalcidol and plain vitamin $d$ on osteoporosis: A randomised controlled trial}

\author{
Janak Das Kathabaniya, Bikram Prasad Shrestha, Rajiv Maharjan, \\ Rosan Prasad Shah and Jeevan Kumar Sharma
}

DOI: $\underline{\text { https://doi.org/10.22271/ortho.2018.v4.i1p.160 }}$

\section{Abstract}

Background: Osteoporosis is "a systemic metabolic bone disease characterized by low bone mass and micro architectural deterioration with a consequent increase in bone fragility with susceptibility to fracture. Multiple drug therapy with Alendronate, Calcium \& plain vitamin D or alfacalcidol has been established to treat osteoporosis. In any patient with healthy liver and kidneys, plain vitamin D is expected to be as good as more active form of vitamin D. This study was conducted to compare the efficacy, safety and cost effectiveness between alfacalcidol and plain vitamin D in addition to Calcium and Alendronate in the management of osteoporosis.

Methods: The Randomized Controlled Trial was conducted in B.P. Koirala Institute of Health Sciences, a tertiary care hospital in Eastern Nepal, over a period of twelve months from January 2013 to December 2014. Patient in group A were given Alfacalcidol, and group B were given plain Vitamin D.

Results: Most of the patients were from the age group 60-69 yrs of age; mean age $65.54 \pm 7.49$. The BMD and T score were recorded at baseline and after treatment. The BMD measured 0.62853 \pm .060241 at baseline and $0.67910 \pm 0.059040$ after treatment and $\mathrm{T}$ score measured $-3.204 \pm 0.5455$ at baseline and $-2.698 \pm 0.5772$ after treatment. There is no statistical significance between the parameters (BMD and T score) of the two groups.

Conclusion: For the first time in Nepal we have shown that the therapy with alfacalcidol and plain vitamin D when used with alendronate and calcium, have similar efficacy and safety, though the cost of the treatment with alfacalcidol was much higher than that of the plain vitamin $\mathrm{D}$ group.

Keywords: Alfacalcidol, BMD, efficacy, osteoporosis, T-score, vitamin D

\section{Introduction}

Osteoporosis is "a systemic metabolic bone disease characterized by low bone mass and micro architectural deterioration with a consequent increase in bone fragility with susceptibility to fracture. Primary osteoporosis is defined as osteoporosis that occurs in an individual who has no endocrinopathy or other disease state that would account for the changes in bone mass. A study done in 1997 projected that 1.2 million women in the UK have osteoporosis, 7.8 million in US. Up to $40 \%$ of women and $13 \%$ of men will have an osteoporotic fracture in their lifetime. With an aging world population osteoporotic fracture is expected to become an epidemic, rising from1.66 million in 1990 to 6.26 million by 2050. ${ }^{[1]}$ Skeletal bone mass is represented by bone mineral density, (BMD), approximations. Dual-energy X-ray absorptiometry (DEXA) is the gold standard for quantifying BMD, because it is easily performed and is the most extensively validated test against fracture outcomes. DEXA scans allow osteoporosis to be diagnosed prior to fracture. In 1994, the World Health Organization, WHO, advocated the use of $\mathrm{T}$ scores to provide quantitative diagnostic criteria for osteoporosis. $\mathrm{T}$ scores represent the number of standard deviations (SD) away from the estimated peak bone mass for a normal young adult. Z scores represent a comparison between, the patient of focus, and a cohort of patients matched for age, weight and ethnicity. The WHO classification based on DEXA apply to Caucasian females. There is not enough data to translate BMD results into fracture risk for men or nonwhite women. Advanced osteoporosis can be diagnosed by plain film radiographic findings of vertebral compression fractures, vertebral height loss and thoracic kyphosis. Most osteoporotic fractures occur at T7 -T8 and T12 -L1 ${ }^{[2]}$. 
A number of drugs have been used to slow down the progress of osteoporosis and, most importantly, to reduce the risk of both vertebral and all nonvertebral fractures, including those of the hip. Plain vitamin D and calcium supplementation have been shown to reduce the incidence of nonvertebral fractures. [3] The bisphosphonates are a new class of compounds that act by selectively inhibiting osteoclast function, and thus bone resorption, during the remodelling cycle of bone turnover. Although the precise mechanism of action has not been defined, the net effect of these compounds appears to be a reversal of the remodelling deficit in patients with osteoporosis, such that bone remodelling leads to gradual increments in bone mass, which are easily detectable by skeletal BMD measurements at either the lumbar spine or the femoral neck. It is now well established that taking bisphosphonates leads to consistent increases in axial BMD, irrespective of the severity of the underlying osteoporosis. It is established that the treatment of osteoporosis increases the bone mineral density and reduces the risk of fractures. In the previous study conducted in the Department of Orthopaedics, BPKIHS, the cut off BMD at which patients tended to sustain fragility fracture is T-score -3.25 (unpublished). ${ }^{[4]}$ It is not known exactly when the bone mineral density increases to astatistically significant value after administration of antiosteoporotic treatment. Multiple drug therapy with Alendronate, Calcium \& plain vitamin D or alfacalcidol has been established to treat osteoporosis. In any patient with healthy liver and kidneys, plain vitamin D is expected to be as good as more active form of vitamin D. This study was conducted to compare the efficacy safety and cost effectiveness between alfacalcidol and plain vitamin $D$ in addition to Calcium and Alendronate in the management of osteoporosis.

\section{Materials and Methods \\ Setting}

The study was conducted in the Department of Orthopaedics, B.P. Koirala

Institute of Health Sciences (BPKIHS), a tertiary care hospital in Eastern Nepal, over a period of twelve months from January 2013 to December 2013. Ethical clearance was obtained from Institutional Ethical Review Board (IERB)

\section{Inclusion Criteria}

- Established postmenopausal or male osteoporosis above 50 years

- $\quad$ Bone Mineral Density T-score $\leq 2.5$

- All persons giving informed written consent for the trial.

\section{Exclusion Criteria}

- Secondary osteoporosis

- All person having age $<50$ years

- Patients already undergoing antiosteoporotic treatment

- All person not giving written consent to participate in the trial

\section{Sample Size: 80 patients (40 in each group)}

\section{Intervention}

DEXA scan was done on volunteers of age above or equal to 50 years. If there $\mathrm{T}$ score was -2.5 or less and meeting other inclusion criteria was considered eligible for the study. They were randomized into two groups according to Excel Random number generation technique.

Group A: Patient receiving Alendronate +Calcium + Alfacalcidol

Group B: Patient receiving Alendronate+ Calcium+ Plain vitamin D

A through history was taken for every eligible patient followed by general systemic examination and local examination. The details of parameters were recorded according to pro forma. Baseline Dual energy $\mathrm{x}$-ray absorptiometry (DEXA) scan of lumbar spine was done to determine severity of osteoporosis in terms of BMD and T score. Treatment was started as per following regime group wise

\section{Group A (Alfacalcidol group)}

Tab. Alendronate $70 \mathrm{mg}$ PO weekly + Tab. Calcium $500 \mathrm{mg}$ PO TDS + Tab. Alfacalcidol $1 \mathrm{mcg}$ daily for one year.

\section{Group B (Plain vitamin D group)}

Tab Alendronate $70 \mathrm{mg}$ PO weekly + Calcium 500mg PO TDS + Plain vitamin D 60,000 IU PO weekly for one year.

\section{Follow Up}

Follow up at 3 month and 6 month was done to check compliance and adverse drug reaction. Follow up at 12 month, DEXA scan of lumbar spine was done to determine effect of treatment on the BMD status and T score.

\section{Parameters / variables to be studied}

- $\quad$ BMD and T score of lumbar spine before and after supplementation of Antiosteoporotic treatment.

- Drug compliance and

- $\quad$ Adverse effect (if any)

\section{Statistical Analysis}

The data was collected in Microsoft EXCEL 2013. Data analysis was done using SPSS 11.5 for Windows (SPSS Inc., Chicago, Illinois) software. Success of randomization was checked by significance of other (nonoutcome) variables between the two groups. Means were compared between the two groups, with 95\% confidence intervals (CI) being considered as statistically significant differences. The unpaired independent $\mathbf{t}$ test and paired $\mathbf{t}$-test were used to compare outcome measures with parametric means. The chisquared test was used to compare non-parametric means. The level of significance was set at $p \leq 0.05$. The results were compared with the other studies in the literature.

Ethical clearance: was obtained from the Institutional Ethical Review Board.

\section{Results}

A total of 248 patients underwent DEXA Scan in the Department of Orthopaedics from January 2013 to December 2013. Out of these 112 patients were diagnosed with osteoporosis. Eighty patients with osteoporosis who satisfied the inclusion criteria were included in the study. 40 patients were randomized into Group A in which they were treated with alfacalcidol along with alendronate and calcium and 40 in Group B who were treated with plain vitamin D along with alendronate and calcium 


\section{CONSORT CHART}

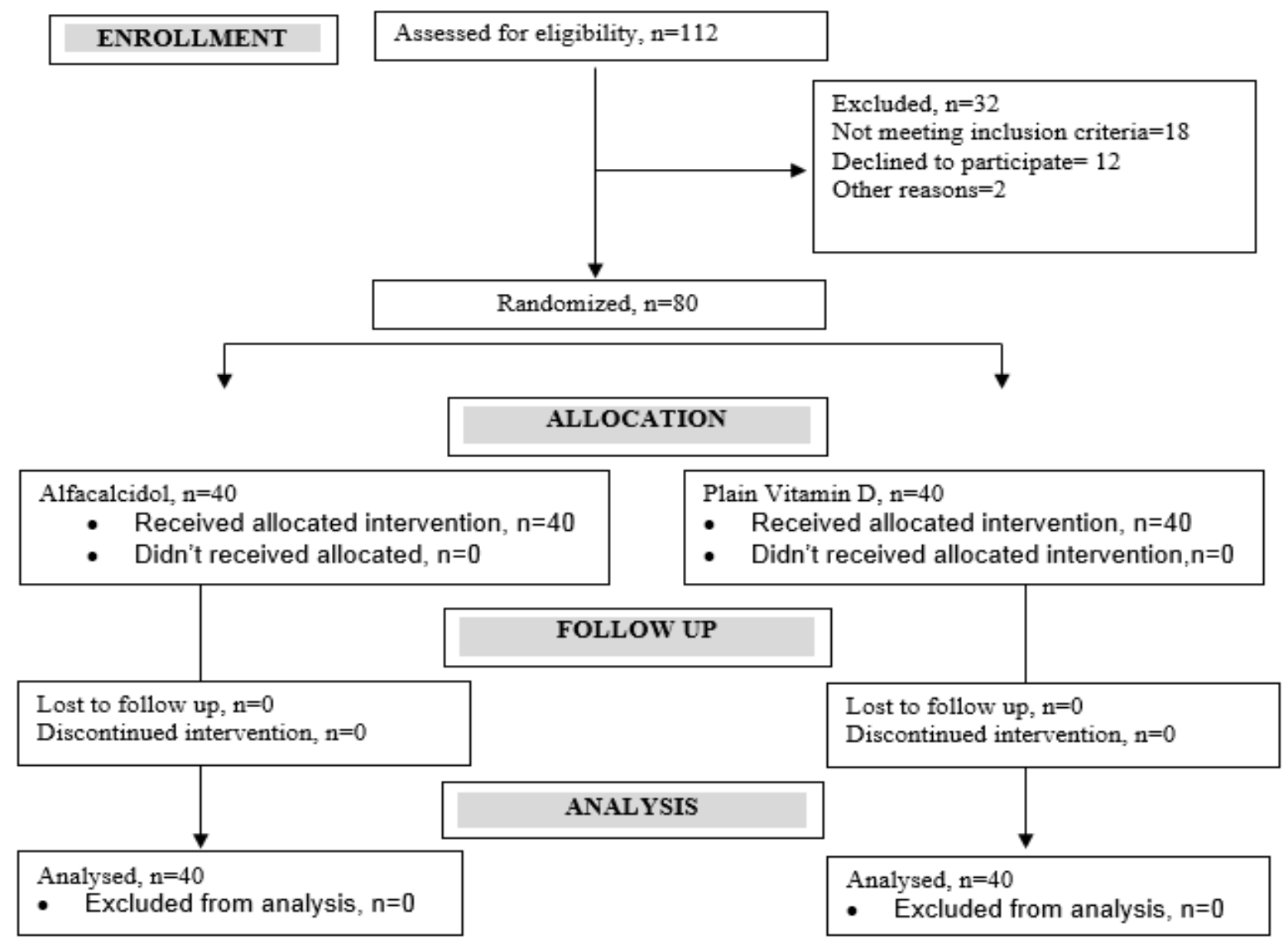

Most of the patients were from the age group $60-69$ yrs of age; mean age $65.54 \pm 7.49$. The numbers of male and female were comparable. Baseline weights, weight after treatment, height baseline and after treatment, Body mass index were also measured.

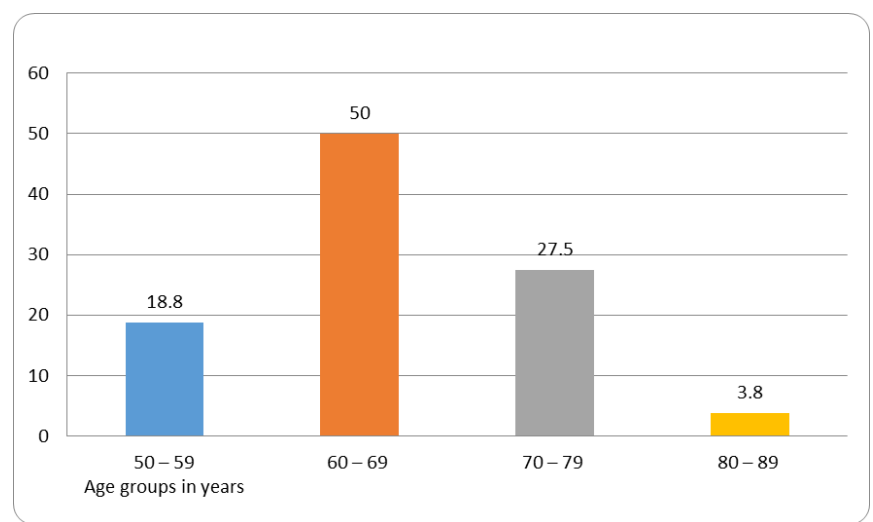

Fig 1: Percentage of patients according to the Age groups

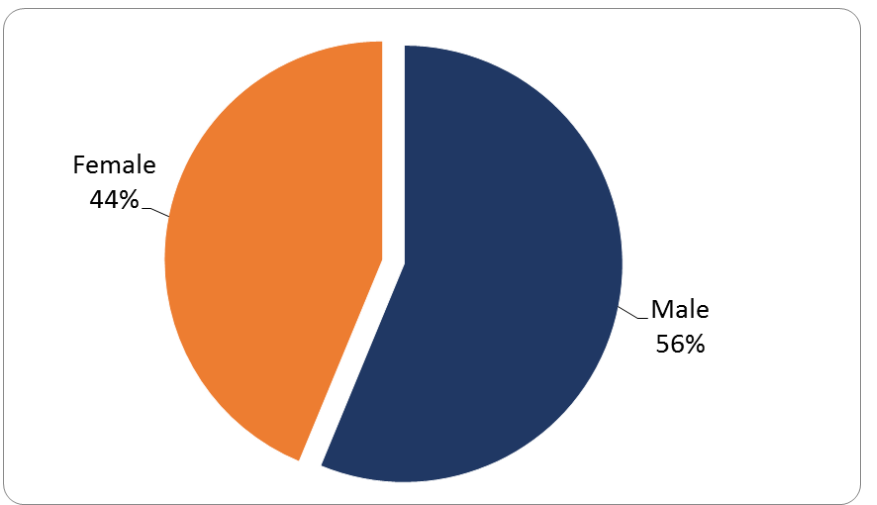

Fig 2: Percentage of patients according to the Gender distribution

Out of the 80 persons studied $56 \%$ were male and $44 \%$ were female. There were $18.8 \%$ in the $50-59 \mathrm{yr}$ age group, $50 \%$ in $60-69 \mathrm{yr}$ age group, $27.5 \%$ in the $70-79 \mathrm{yr}$ age group and $3.8 \%$ in the $80-89$ yr age group.The general characteristics of the 80 patients are elaborated below in Table 1 .

Table 1: Socio demographic characteristics of study population

\begin{tabular}{|c|c|c|c|}
\hline Characteristics & Categories & No of Patients & Percentage \\
\hline \multirow{3}{*}{ Age groups in years } & $50-59$ & 15 & 18.8 \\
\cline { 2 - 4 } & $60-69$ & 40 & 50.0 \\
\cline { 2 - 4 } & $70-79$ & 22 & 27.5 \\
\cline { 2 - 4 } & $80-89$ & 3 & 3.8 \\
\hline \multicolumn{2}{|c|}{$\begin{array}{c}\text { Mean age ( in years) } \pm \text { SD } \\
\text { (Min - Max) }\end{array}$} & Male & $65.54 \pm 7.49(52-86)$ \\
\cline { 2 - 4 } Gender & Female & 35 & 56.3 \\
\hline \multicolumn{2}{|c|}{ Baseline Mean weight (in kg) \pm SD (Min - Max) } & $50.94 \pm 8.23(35-75)$ \\
\hline
\end{tabular}




\begin{tabular}{|c|c|c|c|}
\hline \multicolumn{2}{|c|}{$\begin{array}{l}\text { At } 12 \text { months weight }(\text { in } \mathrm{kg}) \pm \mathrm{SD} \\
\text { (Min - Max ) }\end{array}$} & \multicolumn{2}{|c|}{$50.55 \pm 7.27(35-80)$} \\
\hline \multicolumn{2}{|c|}{ Baseline Mean height $($ in $\mathrm{cm}) \pm \mathrm{SD}($ Min - Max $)$} & \multicolumn{2}{|c|}{$146.68 \pm 8.22(130-164)$} \\
\hline \multicolumn{2}{|c|}{ At 12 month Mean height in $\mathrm{cm} \pm \mathrm{SD}$ (Min - Max $)$} & \multicolumn{2}{|c|}{$146.58 \pm 8.14(130-164)$} \\
\hline \multirow{4}{*}{$\begin{array}{c}\text { Baseline } \\
\text { Body Mass Index }\end{array}$} & $<18.0$ & 1 & \\
\hline & $18.0-24.9$ & 36 & \\
\hline & $25.0-29.9$ & 18 & \\
\hline & $\geq 30$ & 5 & \\
\hline \multicolumn{2}{|c|}{ Baseline Mean BMI \pm SD } & \multicolumn{2}{|c|}{$23.76 \pm 3.20$} \\
\hline \multirow{4}{*}{$\begin{array}{c}\text { At } 12 \text { month } \\
\text { Body Mass Index }\end{array}$} & $<18.0$ & 2 & \\
\hline & $18.0-24.9$ & 35 & \\
\hline & $25.0-29.9$ & 18 & \\
\hline & $\geq 30$ & 5 & \\
\hline \multicolumn{2}{|c|}{$\begin{array}{c}\text { At } 12 \text { month } \\
\text { Mean BMI } \pm \text { SD(Min }- \text { Max })\end{array}$} & \multicolumn{2}{|c|}{$23.61 \pm 3.21(17.31-31.12)$} \\
\hline \multicolumn{2}{|c|}{ Total } & 80 & 100.0 \\
\hline
\end{tabular}

Table 2: Menopausal profile of women

\begin{tabular}{|c|c|c|}
\hline Menopausal history & Categories & No of Patients \\
\hline \multirow{2}{*}{ Age of Menopausal in years } & $<45$ & 14 \\
\cline { 2 - 3 } & $\geq 45$ & 21 \\
\hline Mean age of Menopausal in years \pm SD (Min - Max) & $45.23 \pm 2.91(41-50)$ \\
\hline \multirow{2}{*}{ Duration of menopause } & $<10$ & 2 \\
\cline { 2 - 3 } & $10-20$ & 12 \\
\cline { 2 - 3 } & $>20$ & 21 \\
\hline \multicolumn{2}{|c|}{ Mean duration of menopause in years \pm SD (Min - Max) } & $22.09 \pm 7.35(5-40)$ \\
\hline \multicolumn{2}{|c|}{ Total } & 35 \\
\hline
\end{tabular}

Menopause plays an important role in the development of osteoporosis; hence it could not be overlooked. All the females in the study were postmenopausal. The mean duration of menopause in years was $22.09 \pm 7.35$ years. Table 2 gives details of the menopausal history of women with osteoporosis.

Table 3: Baseline and 12month BMD and T score in Menopausal women

\begin{tabular}{|c|c|c|c|c|}
\hline \multicolumn{2}{|c|}{ Characteristics } & $\mathbf{N}$ & Mean & Std. Deviation \\
\hline \multirow{3}{*}{ Baseline BMD } & $<10$ & 2 & 0.617 & 0.082024 \\
\hline & $10-20$ & 9 & 0.63378 & 0.048759 \\
\hline & $>20$ & 24 & 0.60604 & 0.062269 \\
\hline \multirow{3}{*}{ Baseline $\mathrm{T}$ score } & $<10$ & 2 & -3.15 & 0.9192 \\
\hline & $10-20$ & 9 & -2.989 & 0.3551 \\
\hline & $>20$ & 24 & -3.408 & 0.4699 \\
\hline \multirow{3}{*}{12 Month BMD } & $<10$ & 2 & 0.6775 & 0.061518 \\
\hline & $10-20$ & 9 & 0.67078 & 0.061308 \\
\hline & $>20$ & 24 & 0.65558 & 0.05465 \\
\hline \multirow{3}{*}{12 month_T_score } & $<10$ & 2 & -2.6 & 0.7071 \\
\hline & $10-20$ & 9 & -2.667 & 0.5788 \\
\hline & $>20$ & 24 & -2.963 & 0.3621 \\
\hline
\end{tabular}

The change in mean Baseline BMD was noted in menopausal women with period of menopause $<10 \mathrm{yrs}$ with mean at baseline being $0.617 \pm 0.082024$ and mean at 12 months being $0.6775 \pm 0.061518$, as for women of menopause duration $10-$ 20 yrs mean at baseline being $0.63378 \pm 0.048759$ and mean at 12 months being $0.67078 \pm 0.061308$, and for menopause of $>20$ yrs duration the mean at baseline was $0.60604 \pm$ 0.062269 and the mean at 12 months was $0.65558+0.05465$.

For the T score in menopausal women of duration $<10 \mathrm{yrs}$ of menopause the mean at baseline was $-3.15 \pm 0.9192$ and the mean at 12 months was $-2.6 \pm 0.7071$, as for women of menopause duration $10-20$ yrs the mean at baseline was $2.989 \pm 0.3551$ and mean at 12 months was $-2.667 \pm 0.5788$, as for women with a duration of $>20$ yrs of menopause the mean at baseline was $-3.408 \pm 0.4699$ and the mean at 12 months was $-2.963 \pm 0.3621$.
Table 4: Osteoporosis Measurement of Study population

\begin{tabular}{|c|c|c|c|}
\hline $\begin{array}{c}\text { Reading } \\
\text { time }\end{array}$ & Measurement & Mean \pm SD & Min - Max \\
\hline \multirow{3}{*}{ Baseline } & BMD & $\begin{array}{l}0.62853 \pm \\
0.060241\end{array}$ & $0.514-0.757$ \\
\cline { 2 - 4 } & T Score & $\begin{array}{c}-3.204 \pm \\
0.5455\end{array}$ & $-4.8--2.5$ \\
\hline $\begin{array}{c}\text { After } \\
\text { treatment }\end{array}$ & BMD & $0.67910 \pm 0.059040$ & $0.569-0.798$ \\
\cline { 2 - 4 } & T Score & $-2.698 \pm 0.5772$ & $-4.4--1.6$ \\
\hline
\end{tabular}

The BMD and $\mathrm{T}$ score were recorded at baseline and after treatment. The BMD measured 0.62853 \pm .060241 at baseline and $0.67910 \pm 0.059040$ after treatment and $\mathrm{T}$ score measured $-3.204 \pm 0.5455$ at baseline and $-2.698 \pm 0.5772$ after treatment. 
Table 5: Socio demographic characteristics of osteoporotic patients treated by the two groups: alfacalcidol and plain vitamin D

\begin{tabular}{|c|c|c|c|c|c|}
\hline \multirow[b]{2}{*}{ Socio demographic characteristics } & \multirow[b]{2}{*}{ Categories } & \multicolumn{2}{|c|}{ Treatment group } & \multirow[b]{2}{*}{ P Value } & \multirow[b]{2}{*}{ Remarks } \\
\hline & & $\begin{array}{c}\text { Alfacalcidol } \\
\text { Group }\end{array}$ & $\begin{array}{c}\text { Plain vitamin D } \\
\text { Group }\end{array}$ & & \\
\hline \multirow{4}{*}{ Age groups in years } & $50-59$ & 7 & 8 & \multirow{4}{*}{-} & \multirow{4}{*}{ - } \\
\hline & $60-69$ & 18 & 22 & & \\
\hline & $70-79$ & 13 & 9 & & \\
\hline & $80-89$ & 2 & 1 & & \\
\hline \multicolumn{2}{|l|}{ Mean age in years \pm SD } & $64.33 \pm 7.34$ & $65.75 \pm 7.71$ & 0.801 & Not Significant \\
\hline \multirow{2}{*}{ Gender } & Male & 23 & 22 & \multirow{2}{*}{0.822} & \multirow{2}{*}{ Not Significant } \\
\hline & Female & 17 & 18 & & \\
\hline \multicolumn{2}{|c|}{ Baseline Mean Height ( in cm) \pm SD (Min - Max $)$} & $145.53 \pm 7.93$ & $147.83 \pm 8.46$ & 0.213 & Not Significant \\
\hline \multicolumn{2}{|c|}{ At 12 Month Mean Height $($ in $\mathrm{cm}) \pm$ SD $($ Min - Max $)$} & $145.48 \pm 7.94$ & $147.68 \pm 8.30$ & 0.229 & Not Significant \\
\hline \multicolumn{2}{|c|}{ Baseline Mean Weight (in Kg) \pm SD (Min - Max) } & $49.83 \pm 6.10$ & $52.05 \pm 8.52$ & 0.184 & Not Significant \\
\hline \multicolumn{2}{|c|}{ At 12 Month Weight (in Kg) \pm SD (Min - Max) } & $49.53 \pm 5.92$ & $51.58 \pm 8.36$ & 0.210 & Not Significant \\
\hline \multicolumn{2}{|c|}{ Baseline Mean BMI \pm SD } & $23.72 \pm 3.01$ & $23.80 \pm 3.42$ & 0.918 & Not Significant \\
\hline \multicolumn{2}{|c|}{ At 12 Month Mean BMI \pm SD $($ Min - Max $)$} & $23.60 \pm 3.01$ & $23.63 \pm 3.43$ & 0.968 & Not Significant \\
\hline
\end{tabular}

There were no significant statistical differences in the patient's background data with regard to age, gender, and baseline and after treatment height, weight and BMI (Table 5).
Mean age in years $(\mathrm{p}=0.801)$, Gender $(\mathrm{p}=0.822)$, Baseline BMI $(p=0.918)$ and after treatment BMI $(p=0.968)$ as even in Table 5.

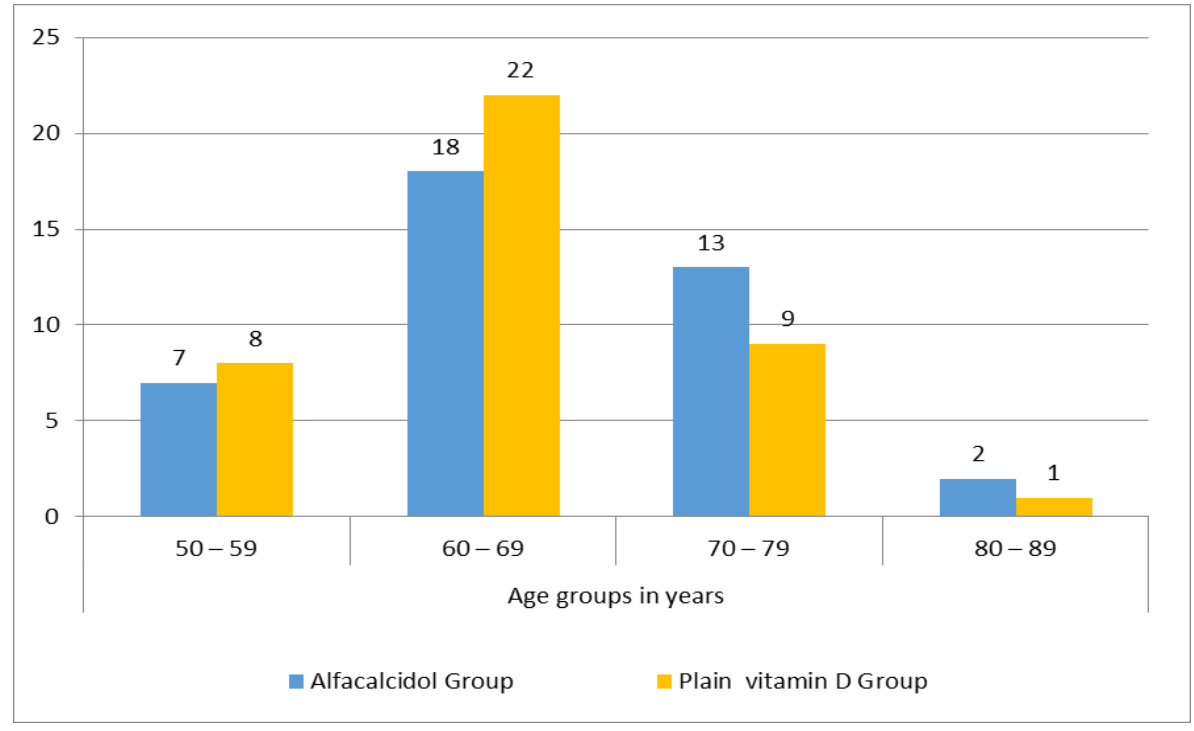

Fig 3: Group wise Age Distribution

Table 6: Socio demographic characteristics of Post - menopausal osteoporotic patients

\begin{tabular}{|c|c|c|c|c|}
\hline $\begin{array}{c}\text { Socio demographic } \\
\text { characteristics }\end{array}$ & \multicolumn{2}{|c|}{ Treatment group } & \multirow{2}{*}{ P Value } & \multirow{2}{*}{ Remarks } \\
\cline { 2 - 5 } & Alfacalcidol Group & Plain vitamin D Group & & \\
\hline Menopausal age & $44.24 \pm 2.41$ & $46.17 \pm 3.09$ & 0.048 & Significant \\
\hline No of menopausal year & $22.53 \pm 7.98$ & $21.67 \pm 6.91$ & 0.734 & Not Significant \\
\hline
\end{tabular}

Women of menopausal age were significant to having osteoporosis with $p=0.048$

Table 7: BMD and T score at Baseline and after treatment in the two groups (patients taking alfacalcidol and plain vitamin D)

\begin{tabular}{|c|c|c|c|c|c|}
\hline \multirow{2}{*}{\multicolumn{2}{|c|}{ Reading time }} & \multicolumn{2}{|c|}{ TREATMENT } & \multirow{3}{*}{$\frac{\text { P Value }}{0.091}$} & \multirow{3}{*}{$\begin{array}{c}\text { Remarks } \\
\text { Not Significant }\end{array}$} \\
\hline & & Alfacalcidol group & Plain vitamin D group & & \\
\hline \multirow{2}{*}{ Baseline } & BMD & $\begin{array}{l}0.61715 \pm \\
0.058602\end{array}$ & $\begin{array}{l}0.63990 \pm \\
0.060427\end{array}$ & & \\
\hline & T Score & $\begin{array}{c}-3.275 \pm \\
0.5246\end{array}$ & $\begin{array}{c}-3.133 \pm \\
0.5631\end{array}$ & 0.245 & Not Significant \\
\hline \multirow{2}{*}{ At 12 month } & BMD & $\begin{array}{l}0.67425 \pm \\
0.061937\end{array}$ & $\begin{array}{l}0.68395 \pm \\
0.056360\end{array}$ & 0.466 & Not Significant \\
\hline & T Score & $-2.722 \pm 0.6095$ & $\begin{array}{c}-2.673 \pm \\
0.5496\end{array}$ & 0.701 & Not Significant \\
\hline
\end{tabular}

There is no statistical significance between the parameters (BMD and T score) of the two groups. 
Table 8: The baseline means of the BMD and $\mathrm{T}$ score of the total sample are as follows

\begin{tabular}{|c|c|c|c|}
\hline & Mean diff. & Baseline Mean & \% \\
\hline BMD & 0.050575 & 0.62853 & $8.05 \%$ \\
\hline T SCORE & 0.5063 & -3.204 & $15 \%$ \\
\hline
\end{tabular}

The change in $\%$ of BMD after treatment was $8.05 \%$ whereas change in T score after treatment was $15 \%$

Table 9: The baseline means of the BMD and T score of the two groups (Alfacalcidol and Plain vitamin D) are as follows:

\begin{tabular}{|c|c|c|c|c|c|c|}
\hline \multicolumn{2}{|c|}{ Measurement } & Mean diff. & Baseline mean & $\%$ & $P$ value & Remarks \\
\hline \multirow{2}{*}{ BMD } & Alfacalcidol & 0.057100 & 0.61715 & $9.3 \%$ & \multirow{2}{*}{0.6997} & \multirow{2}{*}{ Not Significant } \\
\hline & Plain vitamin D & 0.044050 & 0.63990 & $6.9 \%$ & & \\
\hline \multirow{2}{*}{ T -SCORE } & Alfacalcidol & 0.5525 & -3.275 & $16.9 \%$ & \multirow{2}{*}{0.787} & \multirow{2}{*}{ Not significant } \\
\hline & Plain vitamin D & 0.4600 & -3.133 & $14.7 \%$ & & \\
\hline
\end{tabular}

The change in BMD and $\mathrm{T}$ score was statistically insignificance when compared after treatment to the baseline measures in both the groups (Alfacalcidol and Plain vitamin D).

The BMD in the patients treated with alfacalcidol and plain vitamin $\mathrm{D}$ had mean difference 0.057100 and 0.044050 with baseline mean 0.61715 and 0.63990 with a change of $9.3 \%$ and $6.9 \%$ respectively. Likewise, the $\mathrm{T}$ score in the patients treated with alfacalcidol and plain vitamin $\mathrm{D}$ had mean difference of 0.5525 and 0.4600 with baseline mean 3.275 and -3.133 with a change of $16.9 \%$ and $14.7 \%$.

\section{Discussion}

The results of the present study show that both the treatment modalities are beneficial, none being superior to the other. Alfacalcidol and plain vitamin D treatments similarly improved the BMD and the $\mathrm{T}$ score of the osteoporotic patients equally in both the groups.

There was no significant difference between final and baseline BMD ( $\mathrm{p}$ value

0.6997 ) in plain vitamin D group. It can be compared with the study conducted by Aloia et al who studied the effect of vitamin D3 supplementation in calcium-replete, African American postmenopausal women and concluded that there was no observed effect of vitamin D3 supplementation on bone loss or bone turnover markers in calcium-replete African American postmenopausal women. ${ }^{[5]}$

In the present study mean change in BMD was $6.9 \%$, whereas the mean change in $\mathrm{T}$ score was $14.7 \%$. Marcus et al conducted a study in which French women were treated with calcium and plain vitamin D (800 IU/day) and placebo. The study subjects who received calcium and plain vitamin D had significant reductions in hip and non-vertebral fractures and significantly increased femoral neck $(1.1 \%)$ and trochanter (5.4\%) BMD at 18 months compared with placebo. Those women who received calcium and plain vitamin $\mathrm{D}$ had increased total body BMD (1.1\% above placebo) and slight increases in lumbar spine $(0.6 \%)$ and femoral neck $(0.3 \%)$ BMD. ${ }^{[6]}$

The higher change in BMD in our study may be due to concomitant use of Alendronate along with calcium and plain vitamin D. The mean change in BMD in our study was $6.9 \%$ in plain vitamin D group. Adams JS et al. in a period of 2 years concluded that plain vitamin $\mathrm{D}$ repletion was associated with $4-5 \%$ increase in BMD in lumbar spine annually. ${ }^{[7]}$

The greater changes in BMD in the present study could be due to adjunct use of plain vitamin $\mathrm{D}$ with calcium and Alendronate. The present study demonstrated increase in BMD and $\mathrm{T}$ score in both treatment groups. The gain in BMD and $\mathrm{T}$ score increased consistently. These findings confirm the discussed stimulating effect of alfacalcidol on osteoblasts, uncoupled from the inhibition of osteoclasts by Alendronate. Current preclinical and clinical data suggest that, in vitamin D replete patients, as for patients with impaired renal function, therapeutic effects on bone, muscle or other target organs may have better chances to be achieved using D-hormone analogues compared to plain vitamin D due to the bypass of the renal feedback down regulatory system. ${ }^{[8,9,10]}$ Based on these data this study was conducted to check the superiority of the combination of the two pharmacological combinations: Alendronate + Alfacalcidol + Calcium in comparison to Alendronate + plain vitamin D + Calcium. The result of this study does not reflect any profound differences in the efficacy and safety of the two treatment modalities, which can be due to the limited duration of the study period.

In this study there was no statistical significant difference between the final and baseline BMD ( $p$-value 0.6997) in the two groups, alfacalcidol and plain vitamin $\mathrm{D}$, though the percentage change in BMD in alfacalcidol group is $9.3 \%$ and plain vitamin D group is $6.9 \%$. This increase in BMDs suggests gain in compact bone. On the contrary the study conducted by Rus B et al. found that calcium treated group has a tendency towards slower loss of compact bone as compared with the placebo group. ${ }^{[11]}$ In the present study the mean percentage change in BMD in alfacalcidol and plain vitamin D was 9.3 and 6.9 respectively. Bell $\mathrm{NH}$ et al in his study administered $500 \mathrm{mg}$ of elemental calcium, $500 \mathrm{IU}$ of plain vitamin D and $10 \mathrm{mg}$ of alendronate daily for 2 years. He found the mean change in BMD for lumbar spine to be $6.5 \% \pm 0.7 \%$. ${ }^{[12]}$ The difference may be due to the change in dose as in our study, plain plain vitamin D being 60,000 IU weekly and calcium $1500 \mathrm{mg}$ daily for a time period of 1 year only rather than 2 year in their study. Miller PD et al. in their study administered $70 \mathrm{mg}$ alendronate once a week. The mean relative change in BMD at 12 months was $5.8 \%$ in lumbar spine. ${ }^{[13]}$

In this study the mean change in BMD was $9.3 \%$ in the alfacalcidol group and $6.9 \%$ in the plain vitamin D group. This was more than expected but this could be the concomitant use of alendronate, calcium and plain vitamin D. Ringe JD et al. compared the effect of $1 \mathrm{mcg}$ of alfacalcidol and $10 \mathrm{mg}$ of alendronate daily. At the end of 3 years the mean increase in lumbar spine BMD was $3.5 \%$ in alfacalcidol treated group and $11.5 \%$ in alendronate treated group. ${ }^{[14]}$

In this study the mean change in BMD was $9.3 \%$ in the alfacalcidol group and $6.9 \%$ in the plain vitamin D group. This was more than expected from plain vitamin D treated group but less than alfacalcidol treated group. This could be because the duration of this study is not comparable.

In this study the mean percentage change in BMD was $8.05 \%$. The alfacalcidol group had mean percentage change in BMD of $9.3 \%$ and the vitamin D group had a mean percentage 
change in BMD of $6.9 \%$. The mean percentage change in $\mathrm{T}$ score was $15 \%$. The alfacalcidol group had mean percentage change in $\mathrm{T}$-score of $16.9 \%$ and the plain vitamin $\mathrm{D}$ group had a mean percentage change in T-score of $14.7 \%$. The data above shows increase in BMD and $\mathrm{T}$ score after giving calcium, plain vitamin D and alendronate for 1 year. So this study shows similar results to studies done previously by others as stated above. ${ }^{[12,13,14]}$

In the present study the change in mean weight was - $0.39+$ 0.96 , the change in mean height was $-0.1+0.08$ and the change in mean BMI was $-0.15+0.01$. As stated by Reid IR in his study body weight had positive effect on BMD and body weight predicts BMD better than BMI. ${ }^{[15]}$ Morin S et al. stated low body weight and BMI predicts osteoporosis. [16] Asomaning $\mathrm{K}$ et al. stated "the change in risk associated with one unit change in BMI (approximately 5-8 pounds) is of greater magnitude than most of the other modifiable risk factors". [17]

In this study mean body weight and mean BMI decreased but the mean BMD increased. This could be because of the antiosteoporotic treatment provided to them. When comparing the two groups the change in mean height was $-0.05+0.01$ in the group taking alfacalcidol whereas in the group taking plain vitamin $D$, the change in mean height was $-0.15+0$ .16 , which was statistically insignificant. The data was insignificant in relation to change in the mean weight between alfacalcidol and plain vitamin $-0.3+0.18$ and $-0.47+0.16$ respectively.

The most important factor looked for in female patients with osteoporosis in the present study was the duration since menopause. The mean duration of menopause was $22.09+$ 7.35 years. Studies have shown that the rate of bone loss after menopause for following 10 years is about $3 \%$ which gradually tails of and by the age of 75 years it is about $0.5 \%$ per year. ${ }^{[12]}$ Hughes et al. found, in women who had menopause of $\leq 5$ years had rapid bone loss from spine and they were not affected by calcium intake. But in women who had menopause of $\geq 6$ years, calcium prevented bone loss as compared to placebo $(-0.38 \% \pm 0.82 \mathrm{SD}$ Vs $-2.85 \% \pm 0.77$ SD). ${ }^{[18]}$

In the present study increase in BMD was noted and the minimum duration of menopause in this population was 5 years but the BMD gain could not be solely contributed to calcium intake. This could be because along with calcium, vitamin D and alendronate were used.

The mean baseline BMDs were noted different in women with varying periods of menopause. In the group with menopause of less than 10 years duration, the mean at baseline was $0.617+0.082024$ and at 12 months was $0.6775+$ 0.061518 . In the group with menopause of 10 to 20 years duration the mean at baseline was $0.63378+0.048759$ and $0.67078+0.061308$ at 12 months. Similarly in the group with menopause of $>20$ years duration, the mean at baseline was $0.60604+0.062269$ and at 12 months was $0.65558+$ 0.05465 .

In the patients in whom alfacalcidol was administered, the cost of the treatment was NRs. 30,000 per year and in the other group in which plain vitamin D was used, the cost of the treatment was NRs. 8,400 per year.

Our study of 12 months duration did not show any adverse reactions in any of the groups. We are not in a position to comment on the adverse effects of longer duration studies.

The present study has few limitations. Blinding was not performed to design the present study to reflect better actual clinical practice. We had a time constrains to find differences in fall and fracture rates as well as the adverse reactions of the two treatment modalities. The population under study was heterogeneous consisting of both males and females of a wide age distribution (50-86 years). Confounders like presence of other diseases and smoking were prevalent in the study population, which were not studied due to time constrains and might have influenced the outcome. The role of calcium, plain vitamin D and alfacalcidol is well established in prevention and treatment of osteoporosis. Studies have shown different results with their use of these drugs either alone or in combination.

This study cannot comment on the benefit derived from any single drug used. Bone metabolism is an ongoing process, so a longer period of study is required to establish the beneficial effect of our intervention.

To conclude: The use of alfacalcidol and plain vitamin D in the treatment of osteoporosis is well established. This study was conducted to compare the efficacy of the two treatment modalities. We found that after treatment for 12 month, both the modalities have similar efficacy, when tried on a sample of 80 patients with osteoporosis. The measures used to assess the efficacy of the two modalities were BMD and T score. The study was time constrained due to which the side effects of the two modalities could not be established. Changes in the means in the height, weight and BMI were noted but were not statistically significant. Due to small sample size statistical significance was not proven for any group though the increasing changes in the means were noted compared to the baseline for the alfacalcidol group. The duration of menopause was a significant factor determining the severity of osteoporosis in female patients. For the first time in Nepal we have shown that the therapy with alfacalcidol and plain vitamin $\mathrm{D}$ when used with alendronate and calcium, have similar efficacy and safety, though the cost of the treatment with alfacalcidol was much higher than that of the plain vitamin D group.

However, more long term, high-quality comparative studies including more patients are needed to confirm the findings of this study in the management of osteoporotic patients and to assess the adverse reactions and also to note the increase in bone mass, strength and fall and fracture rates in the two treatment modalities.

\section{Acknowledgement}

I would like to acknowledge Dr. Guru Prasad Khanal (Rector and Professor of Orthopaedic Surgery), Dr. Pashupati Chaudhary ( Professor and HOD of Orthopaedic Surgery), Dr. Raju Rijal (Additional Professor, Department of Orthopaedic Surgery), Dr Bishnu Pokharel (Assistant Professor, Department of orthopaedic surgery), Dr.Amit limbu (Assistant Professor, Department of Orthopaedic Surgery),Dr. Pramod Baral (Assistant Professor, Department of Orthopaedic Surgery), Dr. Amit Bikram Shah (Assistant Professor, Department of Orthopaedic Surgery), all my colleagues of BPKIHS for their patience and preparedness to assist me in the making of this research paper.

I am immensely thankful to Mr. D. D. Baral, Additional Professor (Biostatistics) and Dr. Surya R Niraula, Professor (Biostatistics) for their guidance in data analysis.

\section{Declarations}

Funding: None

Conflict of interest: None

Ethical approval: Institutional Ethical Review Board 


\section{References}

1. Gullberg B, Johnell O, Kanis JA. World-wide projections for hipfracture. Osteoporos Int. 1997; 7(5):407-13.

2. Kanis JA. Diagnosis of osteoporosis and assessment of fracture risk. Lancet, 2002; 359:1929-36.

3. Chapuy MC, Arlot ME, Duboeuf F et al. vitamin D3 and calcium to prevent hip fractures in elderly women. $\mathrm{N}$ Engl J Med. 1992; 327(23):1637-42.

4. Amanullah MF. Evaluation of association of fragility fracture and bone mineral density in nepalese population. Department of Orthopaedics, B. P. Koirala Institute of Health Sciences, Dharan, Nepal. 2010.

5. Talwar SA, Aloia JF, Pollack S, Yeh J. Dose response to vitamin D supplementation among postmenopausal African American women. Am J Clin Nutr. 2007; 86:1657-62.

6. Marcus R, Wong M, Heath III H, Stock JL. Antiresorptive treatment of postmenopausal osteoporosis: comparison of study designs and outcomes in large clinical trials with fracture as an endpoint. Endocr Rev. 2002; 23(1):16-37.

7. Adams JS, Kantorovich V, Wu C, Javanbakht M, Hollis BW. Resolution of vitamin D insufficiency in osteopenic patients results in rapid recovery of bone mineral density. J Clin Endocrinol Metab. 1999; 84:2729-30.

8. Shiraishi A, Higashi S, Ohkawa H, Kubodera N, Hirasawa T, Ezawa I et al. The advantage of Alfacalcidol over vitamin $\mathrm{D}$ in the treatment of osteoporosis. Calcif Tissue Int. 1999; 65:311-316.

9. BischoV-Ferrari HA, Dawson-Hughes B, Willett WC, Staehelin HB, Bazemore MG, Zee RY et al. EVect of vitamin D on falls. A meta-analysis. JAMA 2004; 291:1999-2006

10. Richy F, Schacht E, Bruyere O, Ethgen O, Gourlay M, Reginster JY. vitamin D analogs versus native vitamin D in preventing bone loss and osteoporosis-related fractures: a comparative metaanalysis. Calcif Tissue Int 2005; 76:176-186.

11. Rus B, Thomsen K, Christiansen C. Does calcium supplementation prevent postmenopausal bone loss? $\mathrm{N}$ Engl J Med. 1987; 316:173-77.

12. Bell NH, Bilezikian JP, Bone III HG, Kaur A, Maragoto A, Santora AC. Alendronate increases bone mass and reduces bone markers in postmenopausal AfricanAmerican women. J Clin Endocrinol Metab. 2002; 87(6):2792-7.

13. Miller PD, Epstein S, Sedarati F, Reginster JY. Oncemonthly oral ibandronate compared with weekly oral alendronate in postmenopausal osteoporosis: results from the head-to-head MOTION study. Curr Med Res Opin. 2008; 24(1):207-13.

14. Ringe JD, Dorst A, Faber H, Ibach K. Alendronate treatment of established primary osteoporosis in men: 3year results of a prospective, comparative, two-arm study. Rheumatol Int. 2004; 24(2):110-3.

15. Reid IR. Relationships between fat and bone. Osteoporos Int. 2008; 19:595-606.

16. Morin S, Tsang JF, Leslie WD. Weight and body mass index predict bone mineral density and fractures in women aged 40 to 59 years. Osteoporos Int. 2009; 20(3):363-70.

17. Asomaning K, Bertone-Johnson ER, Nasca PC, Hooven F, Pekow PS. The association between body mass index and osteoporosis in patients referred for a bone mineral density examination. J Womens Health (Larchmt). 2006;
15(9):1028-34.

18. Hughes BD, Dallal G, Krall EA, Sadowski A, Sahyoun N, Tannenbaum S. A controlled trial of the effect of calcium supplementation on bone density in postmenopausal women. N Engl J Med. 1990; 323:87883. 